\title{
Cestode Development Research in China
}

\section{Gonghuang Cheng}

Fisheries College, Zhanjiang Ocean University, Jiefang Rd 40, Xiashan Zhanjiang, Guangdong 524025, China

\begin{abstract}
Many scientists in China have done much work about the lifecycles of various cestodes and mainly four types of hosts for these parasites: fish, reptiles (snake), birds (chickens, ducks and geese) and mammals. Main life-cycle research works for cestodes carried out by Chinese scientists are abstracted here and there are only a few that aren't mentioned here because that may be repeating too much. Here we can find that the most important part of cestode development is the larval stages that in the intermediate host and most of the species are undergoing the following five larval stages in the course of ontogenesis: a. oncosphere stage, b. lacuna stage, c. cysticcavity stage, d. scolexformation stage, and e. cysticercoid stage. After a mature cysticercoid is taken by a final host the development will complete in the intestine of the host, then the cestode may be mature and produce gravid proglottids.
\end{abstract}

Keywords: Cestode; Development; Life-cycle; China

\section{Introduction}

Adult cestode parasites in the intestines of the vertebrate and/or human beings. It contains a number of parasties. The taxonomy position of the parasites is as follows: Platyhelminthes, Cestoda. Cestodes that parasitic in human and vertebrates can cause parasitic diseases. Chinese ancestors in Tang dynasty had already been concerned about this. Chao Yuan fang recorded that " ... the worm is an inch in length with white colour..." Discussion of disesase origins, 610 A.D. From Zhao (1983) [1] and it is infected by eating the beef that is roasted by porking with mulberry twigs. So we can see that Chinese ancestors had cestode knowledge much earlier. The little problem is that they take the gravid proglottids as the whole worm and had no complete idea about this worm, nor had recognition of the life-history. The report and research work of cestodes is just modern history and the work comes a little later from foreign scientists.

Taenia saginata and Taenia solium are parasites of the human intestine, and they may cause diseases. The most serious condition is that the cestode larvae parasites can enter in the liver, brain and other important organs, especially the Genus Echinococcus which contains Echinococcus granulosus and E. multilocularis. These parasites take human and sheep as the intermediate hosts but cats and dogs as the final hosts. The development of E. multilocularis larva in the host liver can cause serious results, such as cancer. Echinococcus causes the disease called Echinococcosis and it has spreaded widely in pasturing areas of China. So we need to advise those people that they cannot feed the dogs and cats with the bowels of the goats and cattle so that we may cut the mechanisms for transmission of the disease.

The studies of cestodes before 1960 mainly concern with their taxonomy level but there has been some additional research of them as a life-cycle Liao and Shi (1956) [2]; Tang (1982) [3]; Li (1962)a [4]; Lin (1962)b [5] etc and ultrastructure Li and Arai (1991) [6] as well as in relation to molecular biology Liao and Lu (1998) [7] after then.

According to Professor Lin Yuguang, the number of cestodes species found in China was 213 in 1979 and it reached about 400 recorded by Cheng Gonghuang (2002) [8].

Here we mainly discuss the life-history researches of cestode in China. These research works can be mainly divided into the following
4 aspects: Cestodes of Fishes Liao and Shi (1956) [2]; Tang (1982) [3] ; Cestodes of Snakes Cheng and Wu et al. (2008) [9]; Cestodes of chicken and ducks Lin (1979) [10]; Cestodes of mammals Lin (1962)a [4]; Lin (1962)b [5]; Lin and He (1979) [10]. It is to say representive species of cestodes from fish, snakes and mammals in China have all been studied with their life-history and it takes a long time and hard work to finish these jobs. All the cestodes studied are local species of China.

The author takes great effort to make accordance in the terminology with Chervy (2002) [11]. Although Chervy L [11] gave a detail about the terminology of cestode larvae he did not mention the 5 development stages of larval cestode clearly and lack host introduction for most larvae so this paper may be supplementary to that.

\section{Study on development of fish's cestodes}

Mainly three species of fish cestodes were studied by Chinese scientists. We take two of them as examples.

Bothriocephalus gowkongensis: Bothriocephalus gowkongensis is a species that caused the disease of larval fishes in Guangdong in 1950s and the life-history of the species was studied by Liao Xianghua and Shi Liuzhang in 1956 [2].

Eggs, coracidium, procercoid, plerocercoid and adult stages were found in the life history of the worm. (Figure 1-9). The egg developed in freshwater for $3 \sim 5$ days to complete hatching in $28 \sim 30^{\circ} \mathrm{C}, 10 \sim 20$ days in $14 \sim 15^{\circ} \mathrm{C}$. Coracidium is spherical with 3 pairs of falciform hooks in the end, and there are cillia in the outside membranes of the larva. It vibrates all the time for a whole day and then stops and can survive in water for 2 days. It develops into procercoid when it vibrates in the water if it is taken by Mesocyclops leuckarti or Thermocyclops

Corresponding author: Gonghuang Cheng, Fisheries College, Zhanjiang Ocean University, Jiefang Rd 40, Xiashan Zhanjiang, Guangdong 524025, China, Tel: +8613828291964, E-mail: ghcheng@sohu.com

Received October 13, 2011; Accepted November 16, 2011; Published November 21, 2011

Citation: Cheng G (2011) Cestode Development Research in China. J Veterinar Sci Technol S3:002. doi:10.4172/2157-7579.S3-002

Copyright: (c) 2011 Cheng G. This is an open-access article distributed under the terms of the Creative Commons Attribution License, which permits unrestricted use, distribution, and reproduction in any medium, provided the original author and source are credited. 

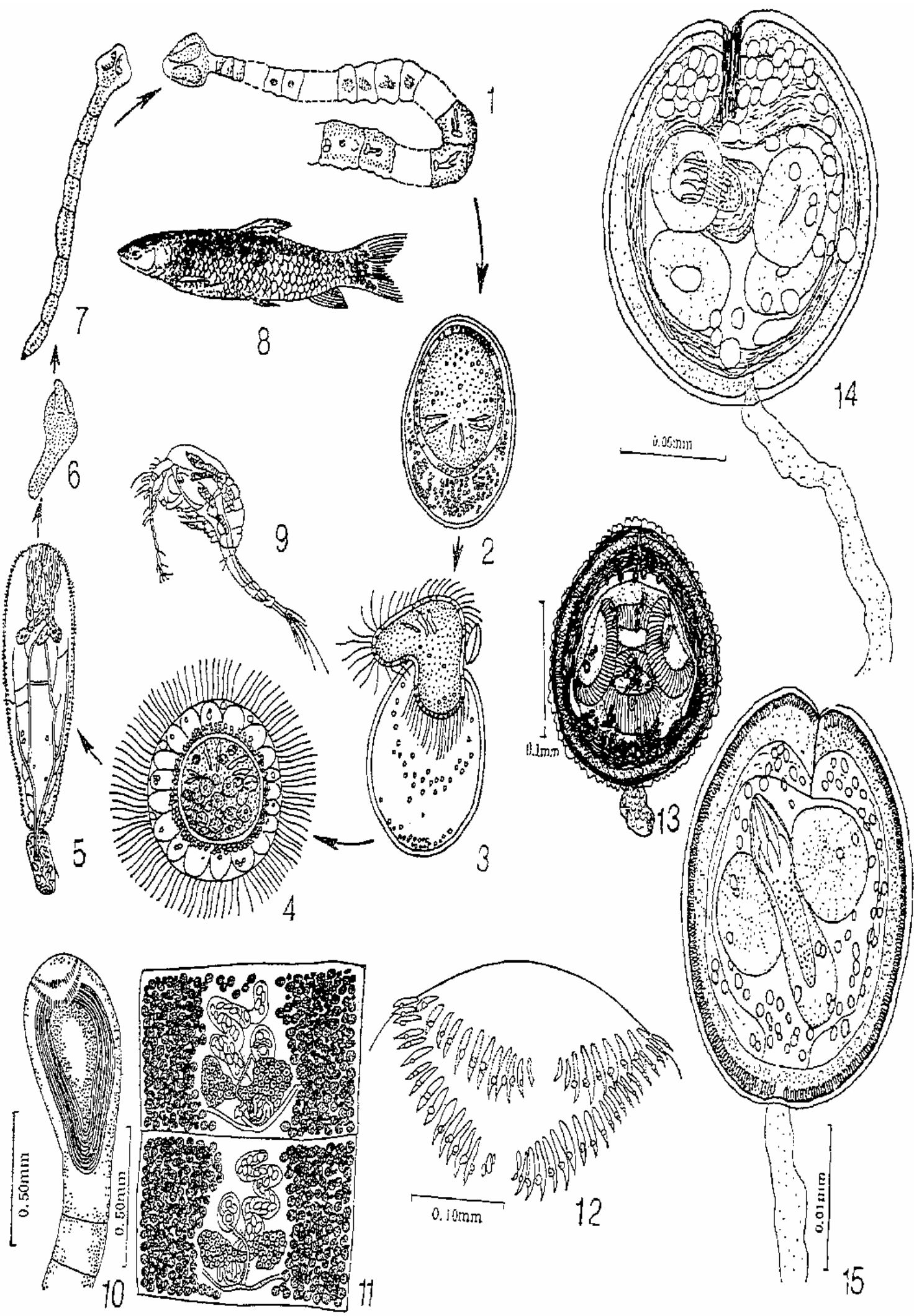

Explanation for the Plate

Figure 1: 1-9 the life-cycle of Bothriocephalus gowkongensis; 10-12 Polyoncobothrium ophiocephalina: 10.scolex, 11. mature proglottid, 12. hooks above the scolex 13 cysticercoid of Hymenolepis venusta, 14 cysticercoid of Fimbriaria fasciolaris 15 cysticercoid of $P$. ryjikovi. 
taihokuensis as food, and it gets through the gut to the cavity and needs 5 days to become procercoid. Procercoid is a little long body and with a spherical tail aparatus, where the 6 hooks remain and there are $4 \sim 5$ pairs of penetration glands in the head of the larva. Procercoid can live in the host until it reaches to a new predator. If the cyclops with procercoids is taken by a carp the procercoid can develop into a plerocercoid in the intestine of the fish and it is still not segmented. And it takes about 11 days to develop into an adult worm. The plerocercoid need $21 \sim 23$ days to reach mature in $28 \sim 29^{\circ} \mathrm{C}$ in the summer.

Polyoncobothrium agnum (Zmeev 1936) and P. ophiocephalina (Tseng 1933) [3]: The life cycle of these two species was described by Tang (1982) [3] (Figure 10-12). The egg becomes mature after about 3 days in $22 \sim 29^{\circ} \mathrm{C}$ room temperature. Miracidium hatched from swimming in the water. Its body length is $65 \mu$ in diameter, with a cilia embryopore up to $5 \sim 16 \mu$. In the middle there is a onchosphere with a diameter of $60 \sim 64 \mu$. At the front of the onchosphere there are 2 unicell penetration glands. Mesocyclops leuckarti or Thermocyclops taihokuensis may be taken as the intermediate host of the parasite. The oncosphere invaded into the cavity of the cyclops and developed into a spherical larva then becomes narrow and elongates. The tail comes out about 15 days in the temperature of $21 \sim 23^{\circ} \mathrm{C}$; after 18 days it becomes plerocercoids. The length of the body is $0.40 \times 0.18 \mathrm{~mm}$, with a tail of $0.24 \mathrm{~mm}$. There are 7 8 pairs of penetration glands in the middle of the body. It may survive for 30 days in the body of a cyclops. After infection with the eel the larva can be seen with a 8-shaped cycle of hooks in 3 days at the top of its body which can become more than 50 hooks in 7 days. This is the adult stage.

\section{Study on development of Snake Cestodes}

Ophiotaenia monnigi: This was recently reported by Cheng, $\mathrm{Wu}$ et al. (2008) [9].

Cyclops leuckarti and C. prasinus can serve as the intermediate hosts of Ophiotaenia monnigi, Fuhrmann (1924) [9]. From the hexacanth, the parasite developed to a mature procercoid larva without a cercomere, although it appeared in the development processes. At the two-part development stage, all the hooks transferred to the cercomere, and it dropped off in the latest time of the larval development. In the development, a coelom presented in the front part as well as in the cercomere. An apical organ appeared, and two pairs of gland cells were found after the sucker. The whole developmental course took more than 11 days, and it was even longer in the host, C. prasinus, in which the parasite larva developed slower.

\section{Study on development of Cestodes from chicken and ducks}

This was mainly reported by Su Xinzhan and Professor Lin Yuguang (1987) [12] and his colleagues.

The development of larval stages within the hemocoele of interediate hosts of five species of cestodes, namely Hymenolepis venusta (Figure 13), H. setigera, Fimbriaria fasciolaris (Figure 14), Drepanidotaenia lanceolata and Diochis stefanskii. And the specific characters of each stage of larvae, especially their cysticercoids, were carefully studied and compared by those authors. It was revealed that these cestodes had a general pattern in the course of their oncogenesis. The process of larval growth can be divided into five stages: a. oncosphere stage, b. lacuna stage, c. cysticavity stage, d. scolex formation stage, and e. cysticercoid stage. Based on the observations, the features of these hymenolepidae cysticercoids, including the shape and size of cysticercoid, the cystic wall and fibrous membrane, the shape, size and number of rostellar hooks etc. can be identified as the specific diagnostic characters of species.

\section{Study on development of mammal Cestodes}

There are many mammal cestodes in China and many of them have been studied with their life cycle, for example: Hymenolepis diminuta and H. nana; Pseudanoplocephala crowfordi; Moniezia benedeni and M. expansa.

Moniezia benedeni and M. expansa: The life-cycle of Moniezia expansa is as follows: natural infection of larva to soil mite in $27 \sim 35^{\circ} \mathrm{C}$ takes 26 30 days for the cysticercoid to become mature, and 40 days for whole maturity. These systicercoids can only infect the lamb and get the adult worm. The intermediate hosts for the cestode development are as follows: Galumna longipluma; G. virginiensis; G. curvum; G. sp.; Scheloribates chauhani; S. laevigatus; Oribatella sp. Peloribates banksi and so on. For M. benedeni, the cysticercoid needs to develop 100 120 days to mature, and its good hosts are Scheloribate laevigatus and Galumna obvious, and another Scheloribates species was proved to be a proper host too.

Hymenolepis diminuta and $\boldsymbol{H}$. nana: The development history was reported by Lin Yuguang in 1962 [4,5]: from egg to mature cysticercoid and with infection needs at least 10 days' development in the intermediate host at the temperature of about $30^{\circ} \mathrm{C}$. The larva takes the following 5 stages in the intermediate host: a. oncosphere; b. lacuna primitiva; c.bladder cavity; d. scolex-formation; e. cysticercoid. And there are many insects which can serve as its intermediate host: Asopia farinalis larva; Akis spinosa, Scaurus striatus; Tribolium ferrugineum, Tenebrio molitor; Fontaria virginaica, Julus sp. Ceratopyllus fasciatus, Xenopsylla cheopis, Leptopsylla musculi, Pulex iritans, Ctenocephalus canis; Pyralis farinalis, Aglossa dimidiata, Tinea granella, T. pellionella, Paralipsa gularis etc. For $H$. nana the larval stage in an intermediate host(Tribolium ferrugineum) development needs 8 days to be infected at $30^{\circ} \mathrm{C}$ Others are quite similar to $H$. diminuta but with fewer hosts.

Paranoplocephala. Ryjikovi: During the autumn of 1980 the soil mites of Oribatei were fed with the gravid proglottides of Paranoplocephala. ryjikovi and dissected at various intervals.The growh and development of the cysticercoid, as observed in the infected mites, were studied in detail by Lin Yuguang [4,5], Guan Jiazhen, Wang Pengpeng et al. [13]

In the incubator temperature ranging from $29 \sim 31^{\circ} \mathrm{C}$, the development of embryo to a cysticercoid within mite hemocoele required 36 42 days after infection, and the fully developed cysticercoids were obtained from 49 80days. The mature cysticercoid is oval in shape, measuring $0.198 \times 0.172 \mathrm{~mm}$ in diameter. The outer cuticle is dark in colour with $3.6 \sim 10.8 \mu$ thickness, having an irregularly undulating membrane around the surface of the cuticle.The outer cystic wall contains two layers of parenchymous cell, being 3.6 10.8 $\mu$ in thickness. The innner cystic wall is fibrous, measuring $14.4 \sim 18.0 \mu$ in thickness. A large number of calcarous bodies are distributed between the scolex and the wall of the cyst. The caudal appendage is degenerated as a sac, measuring $50.4 \mu$ in length and $36.0 \mu$ in width. Three pairs of embryonic hooks and lacunae remain in the tail.

Nine species of oribatid mites, belonging to five families and five genera, were collected from the turf samples of pastures in Hong-yuan district. Four of them namely Scheloribates chauhani, Scheloribates sp.I, Galumna virginiensis and Parakalumma lydia were experimentally proved to be the intermediate host of $P$. ryjikovi. The infection rate with mature cysticercoids for the four species of mite victims were Scheloibtes chauhani 12.5\%, Scheloribates sp. I 69.64\%, Galumna virginiensis $14.78 \%$ and Parakaluma lydia $11.11 \%$. 
The larval development of $P$. ryjikovi from oncosphere to matue cysticercoid (Figure 15) in the intermediate host mainly pass through five larval stages in the course of ontogenesis: a. oncosphere stage, b.lacuna stage, c. cysticavity stage, d. scolex-formation stage, and e. cysticercoid stage. It is considered probale that other species of anoplocephalids of which life cycles are still unknown may also pass through the same course of ontogenesis with the soil mites of Oribatei serving as the intermediate host.

These are the main life-cycle research works for cestodes carried out by Chinese scientists and there are some others that weren't mentioned here, which is because that may be repeating too much. Here we can find that the most important part of cestode development is the larval stage in the intermediate host and most of the species are undergoing the following five larval stages in the course of ontogenesis: a. oncosphere stage, b.lacuna stage, c. cysticcavity stage, d. scolex-formation stage, and e. cysticercoid stage. After a mature cysticercoid is taken to a final host the development will be complete in the interstine of the host, then the cestode may be mature and produce gravid proglottids.

\section{Acknowledgement}

Thanks are due to the Reviewer \#2 of the paper who gave very important criticism to this paper and made a big change of the manuscript.

\section{References}

1. Zhao WX editor in chief (1983) Human Parasitology, People's medical publishing house. Beijing: 484 491

2. Liao XH, Shi LZ (1956) A fry disease of Guangdong, the life-cycle, ecology and prevention of Bothriocephalus gowkongensis. Bulletin of hydrobiology 2 129 186

3. Tang CC (Tang Zhongzhang) (1982) Developmental studies on Polyonchobothrium ophiocephalina (Tseng, 1933) and bothriocephalus opsariichthydis (Yamaguti, 1934). Acta Zoologica Sinica 28: 53 59

4. Lin Y (1962)a Studies on the development of Moniezia expansa (Rudolphi,1810) and its intermediate host. Journal of Fujian Normal College 2: 5 68

5. Lin $Y$ (1962)b Comparative studies on the development of cysticercoid for Hymenolepis expansa and $H$. nana within the intermediate hosts. Journal of Fujian Normal College 2: 263 283

6. Li M, Arai HP (1991)On the ultrastructure of the scolex tegument, organelles and sensory receptors of Gloridacris catostomi Cooper (Cestoda: Caryophyllidea) Acta Zoologica Sinica 37: 113 122

7. Liao XH, Lun ZR (1998) Taxonomy and relatives studies for Bothriocephalus opsariichthydis parasitic in grass carp, carp and opsariichthyd in China. Science Bulletin 43: 1073 1076

8. Cheng GH (2002) Studies on the cestodes in China. China women publishing house Beining: 3 49

9. Cheng G Wu Z and Lin Y (2008) The experimental development of Ophiotaenia monnigi Fuhrmann, 1924 in Cyclops leuckarti. Parasitol Res: 791-794

10. Lin Yuguang (1979). Catalog of Cestodes in China, memoir of the meeting for Cestoda fauna in China

11. Chervy $L$ (2002) The terminology of larval cestodes or metacestodes. Syst Parasitol 52: 1-33

12. Su XZ, Lin $Y$ (1987) Studies on the developmental cycle of cestodes from domestic ducks and geese in Xiamen China. Acta Zoologica Sinica 33: 334 340

13. Lin Y, Guan JZ, Wang PP, Yang WC (1982) Studies on the developmental cycle of Paranoplocephala ryjikovi Spassky (1950) in the intermediate host. Acta Zoologica Sinica 28: 262 271
This article was originally published in a special issue, Veterinary Clinical Pathology handled by Editor(s). Dr. Diana L. Eubanks, Mississippi State University, USA; Dr. J. Jill Heatley, Texas A\&M University, USA 